\title{
Tissue Repairing Activity of Glycosmis pentaphylla Leaf Extract on Oreochromis mossambicus Against Arsenic Induced Toxicity
}

\author{
U. V. Aswathy*, S. Abhirami**, S. R. Flanet Raj* and G. Prasad**† \\ *Department of Zoology, Nesamony Memorial Christian College, Marthandam, Tamil Nadu, India \\ **Department of Zoology, University of Kerala, Kariavattom, Thiruvananthapuram, Kerala, India \\ †Corresponding author: G. Prasad; probios1@gmail.com
}

Nat. Env. \& Poll. Tech.

Website: www.neptjournal.com

Received: 16-04-2021

Revised: 03-05-2021

Accepted: 25-05-2021

\section{Key Words:}

Oreochromis mossambicus

Glycosmis pentaphylla

Karyolysis

Histopathology

\section{ABSTRACT}

Acute toxicity of arsenic to Tilapia (Oreochromis mossambicus) and tissue repairing activity of Glycosmis pentaphylla leaf extract and its histological impacts on gill, liver, and kidney tissues were evaluated. Fish were divided into six groups viz. control, group 1, group 2, group 3, group 4, and group 5. $4.87 \mathrm{ppm}$ of $\mathrm{NaAsO}_{2}$ was administrated in group 1, group 3, and group 5. In group 3, after arsenic exposure, $2.5 \mathrm{~g}$ of leaf extract of Glycosmis pentaphylla per $\mathrm{kg}$ of fish food was added. In group $5,5 \mathrm{~g}$ of $\mathrm{G}$. pentaphylla leaf extract per $\mathrm{kg}$ of fish food was added. In group 2, $2.5 \mathrm{~g}$ of leaf extract per $\mathrm{kg}$ of fish food was added and in group $4,5 \mathrm{~g}$ leaf extract per $\mathrm{kg}$ of fish food was added. The control group showed normal histology of the gill, liver, and kidney. The histological observations revealed the tissue repairing activities in group 2 fish's gill, liver, and kidney. These results revealed the protective and tissue repairing potential of $G$. pentaphylla as a feed supplement against $\mathrm{NaAsO}_{2}$ induced toxicity.

\section{INTRODUCTION}

Arsenic (As) is a moderately toxic, naturally abundant element with no known nutritional or metabolic roles. The chemical form of arsenic in the surface water is dependent on redox potential, $\mathrm{pH}$, and biological processes; however, the thermodynamically stable arsenate predominates in both freshwater and saltwater. Arsenic concentrations are much more variable in freshwater than in estuaries and oceans. Natural and anthropogenic sources can cause a high concentration of arsenic in freshwater without apparent effects on fish. Approximately $90 \%$ of As in fish is organic As, with arsenobetaine being the dominant species in marine fish; speciation in freshwater fish is much more variable. Except in the case of unusually high inorganic waterborne and food exposure, few environmental situations caused fish to lose their homeostatic regulatory mechanisms (McIntyre \& Linton 2012). Bioaccumulation occurs when freshwater creatures, such as fish, are continuously exposed to low levels of As, particularly in the liver and kidney. As a result, As causes hyperglycemia, enzymatic activity depletion, acute and chronic toxicity, as well as immune system malfunction (BibhaKumari et al. 2016).

Arsenic exists in the environment as pentavalent $\left(\mathrm{As}^{5+}\right.$, arsenate) and trivalent ( $\mathrm{As}^{3+}$, arsenite) forms and arsenite has been considered to be more toxic when compared with arsenate (Domingo 1995). On absorption, arsenic is stored in the liver, kidney, heart, and lungs. A lower amount of arsenic is observed in muscles and neuronal tissues (Klaassen 1996). The accumulation of arsenic in these tissues is associated with many disorders including cancer, diabetes, hepatotoxicity, neurotoxicity, and cardiac dysfunction. Acute arsenic poisoning is associated with nausea, vomiting, abdominal pain, and severe diarrhea (Ratnaike 2003).

Nature has provided a source of medicinal agents for thousands of years and an impressive number of modern drugs have been isolated from natural sources, many based on their use in traditional medicine (Cragg \& Newman 2002). Calotropis gigantea is used in some parts of India for wound healing in combination with other plants (Ahmed et al. 2005, Chitme et al. 2004, Argal \& Pathak 2005).

Stems and fruits of Glycosmis pentaphylla are used by medicinal practitioners in Bangladesh for the treatment of rheumatoid arthritis (Mohammed et al. 2010). Roots were used in India against facial inflammation, rheumatism, jaundice, and anemia (Oudhia et al. 2007). Leaf juice along with gingili oil is used internally as a vermifuge (Sivarajan \& Balachandran 1994).

The aim of the present study was to examine the efficacy of tissue repairing activity of $G$. pentaphylla leaf extract on Oreochromis mossambicus against arsenic-induced toxicity. 


\section{MATERIALS AND METHODS}

\section{Experimental Design}

The experimental fish $O$. mossambicus was identified from the Department of Zoology, University of Kerala. Fishes with an average body weight of $75.67 \pm 5 \mathrm{~g}$ and an average length of $13 \pm 1.65 \mathrm{~cm}$ were used for the experiment. The fishes were raised in aerated glass aquaria of about $50 \mathrm{~L}$ capacity and acclimatized for two weeks before the experiment. In this study, fishes were exposed to $4.87 \mathrm{ppm}$ of waterborne $\mathrm{NaA}$ $\mathrm{sO}_{2}$ which correspond to $10 \%$ of the $96 \mathrm{~h} \mathrm{LC50}$. The stock solution of $1000 \mathrm{ppm} \mathrm{NaAsO}_{2}$ was prepared with deionized water and further diluted to the required concentrations. After the acclimation period, the fish were randomly divided into 6 groups containing 6 fishes in each group.

\section{Collection of Plant Material}

The fresh leaves of $G$. pentaphylla were collected from the University of Kerala campus, Kariavattom.

\section{Preparation of Plant Extract}

The collected plant leaves were washed, cut into small pieces, and air-dried in shade for 2 weeks. They are crushed into a fine powder using a grinder, which was used for the preparation of aqueous leaf extract using the Soxhlet apparatus.

\section{Determination of the 96-h LC50 of Sodium Arsenite on O. mossambicus}

An acute toxicity experiment was conducted to determine the 96-hour LC50 value for $O$. mossambicus exposed to sodium arsenite. Design and calculation for the acute toxicity experiment were done based on the procedure of Finney (1952). The LC50 values are derived from the curve drawn using working probits and log doses. Antilog of the dose corresponds to respective probit value (Finney 1952).

\section{Experimental Diet Formulation}

A Basal diet that included $43 \%$ crude protein was formulated by an Excel-based feed formulating software. One control and two experimental feeds were compounded by adding 0 , 2.5 , and $5 \mathrm{~g} . \mathrm{kg}^{-1}$ of leaf extract to the basal diet. Dry fishes were purchased from the local market, washed and dried in a hot air oven at $60^{\circ} \mathrm{C}$ to constant weight, and then powdered. All the other feed components were cleaned, powdered. The feed components were thoroughly mixed and made into a hard dough by adding a sufficient quantity of water. The dough was pressure cooked at $15 \mathrm{lb} . \mathrm{sq}$ inch $^{-1}$ for 15 minutes. Vit/min mix, leaf extract and cod liver oil were added to the dough and extruded in the form of noodles using an extruder having $1 \mathrm{~mm}$ diameter perforations. The pellets were dried at room temperature and then dried in a hot air oven at $60^{\circ} \mathrm{C}$ for 6 hours and stored in airtight containers.

\section{Histological Analysis}

Fishes were slit open ventrally from head to the anus to expose the organs. The organs which include the gill, liver, kidney were removed and fixed in Bouin's solution. The specimens were processed as usual in the recognized method of dehydration, cleared in xylene, and processed for paraffin embedment. Thin sections of tissues were cut using a rotary microtome. They were stained with hematoxylin and eosin (H\&E) stain. Finally, the slides were observed under a Labomed microscope at 100x and 400x magnification and photomicrographs were taken using MICAPS micro view software 3.7 version.

\section{RESULTS AND DISCUSSION}

In the present study, the 96-hour LC50 of $O$. mossambicus against $\mathrm{NaAsO}_{2}$ was determined as 4.8790 ppm with $95 \%$ confidence intervals. The proximate analysis of the experimental feed revealed that the prepared feed consists of $43.57 \%$ of crude protein, $3.62 \%$ of crude fiber, $7.77 \%$ ether extract, $9.32 \%$ of total ash, $11.27 \%$ of moisture content, and $4319 \mathrm{kcal} / \mathrm{kg}$ of gross energy. No mortality was observed in any of the aquaria during the 30 days experimental period. Increased irritability, mucus secretion, color changes, swimming in the surface water were important notable alterations evidenced in the fish groups exposed to sodium arsenite.

\section{$H$ and E Staining}

In the present study, the histological studies were carried out for the control, Arsenic and G. pentaphylla treated fish gill, liver and kidney.

Plate 1A-1C: Gill, Liver, Trunk kidney (X100). PL: Primary Lamellae; SL: Secondary Lamellae; D: Basal cells; H: Hepatocytes; S: Sinusoid; A; Pigment; P: Pancreas; BV: Blood Vessel; GL: Glomerulus; BS: Bowman's Space; CT:

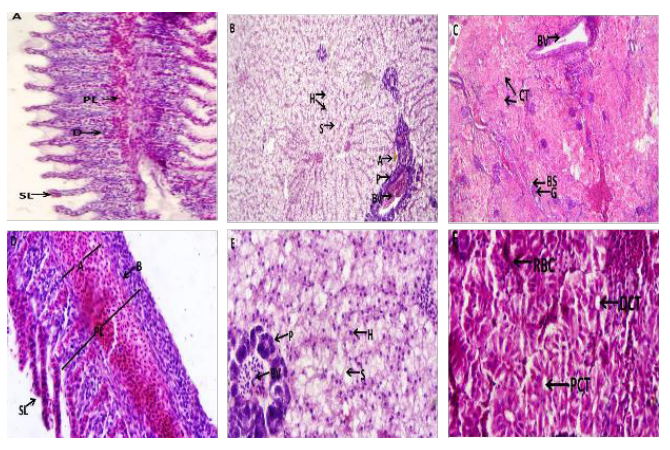

Fig 1: Plate 1: Control group: Fed with normal fish food. 
Collecting Tubule; BV: Hepatic Portal Vein.

Plate 1D-1F: Gill, Liver, Trunk kidney (X400). PL: Primary Lamellae; SL: Secondary Lamellae; B: Basal cells; A: Central Venous Sinus; P: Pancreas; H: Hepatocytes; S: Sinusoid; BV: Blood Vessel; RBC: Red Blood Cells; DCT: Distal Convoluted Tubule.

Plate 2A-2C: Gill, Liver, Trunk kidney (X100). H: Hemorrhage; A: Curling; HY: Hyperplasia; N: Necrosis; LV: Lipid Vacuoles; A: Apoptosis; P: Pigment; CV: Central Vein; LI: Lymphocytic Infiltration; D, N: Degeneration and Necrosis.

Plate 2D-2F: Gill, Liver, Trunk kidney (X400). H: Hemorrhage; D, N: Desquamation and Necrosis; C: Curling; A: Aneurysm; D: Degeneration; HY: Hyperplasia; PN; Pyknotic nuclei; LV: Lipid Vacuoles; LI: Lymphocytic Infiltration; MC: Mild Congestion; K: Kupffer Cells; DH: Degenerated Hepatocytes; EL: Epithelial Lifting: V: Vacuole Formation.

Plate 3A-3C: Gill, Liver, Trunk kidney (X100). PL: Primary Lamellae; SL: Secondary Lamellae; H: Hepatocyte; S: Sinusoid; A; Pigment; P: Pancreas; G; Glomerulus; CT: Convoluted Tubules.

Plate 3D-3F: Gill, Liver, Trunk kidney (X400). EC: Epithelial Cell; M: Mucous Cell; SL: Secondary Lamellae; K: Kupffer Cells; P: Pancreas; S: Sinusoid; CT; Convoluted Tubule; GB: Glomerular Blood; CE: Capsular Endothelium; BC: Bowman's capsule.

Plate 4A-4C: Gill, Liver, Trunk kidney (X100). N: Necrosis; HP: Hyperplasia; C: Congestion; H: Hepatocyte; S: Sinusoid; CV: Central Vein; PA: Portal Area; V: Vacuole Formation; G: Glomerulus; M: Melanomacrophages.

Plate 4D-4F: Gill, Liver, Trunk kidney (X400). MC: Mucous Cell; RBM: Rupture Basement Membrane; HY: Hyperplasia; LV: Lipid Vacuoles; H: Hepatocyte; MC: Leucocyte Infiltration; CV: Cytoplasmic Vacuolation; V: Vacuole Formation; MC; Mild Congestion; K: Karyorrhexis.

Plate 5A-5C: Gill, Liver, Trunk kidney (X100). N: Necrosis; HP: Hyperplasia; C: Curling; S: Shortening of Secondary lamellae; SL: Malformed Secondary lamellae; H: Hepatocyte; S: Sinusoid; P: Pancreas; N: Mild Necrosis; K: Karyolysis; H: Severe Hemorrhage; N: Necrosis; V: Vacuole Formation; NR: Necrosis of renal cells.

Plate 5D-5F: Gill, Liver, Trunk kidney (X400). HP, HT: Hypertrophy, Hyperplasia; SL: Secondary Lamellae; H: Hemorrhage; NP: Necrotic Pancreas; AB: Apoptotic Body; $\mathrm{N}$ : Necrosis; LV: Lipid Vacuoles; LC: Multinucleated Large Cell; K: Karyorrhexis: KL: Karyolysis; V: Vein; N: Tubular Necrosis; C: Congestion.

Plate 6A-6C: Gill, Liver, Trunk kidney (X100). RBM: Rupture Basement Membrane; HP, HT: Hypertrophy, Hyper- plasia; C: Congestion; LF: Lamellar Fusion: H: Hepatocyte with enlarged nuclei; BD: Bile Duct; LV: Lipid Vacuoles; H: Hemorrhage; N: Necrosis; TN: Tubular Necrosis; V: Vacuole Formation; IH: Intertubular Hemorrhages; D: Degeneration of cells. Plate 6D - 6F: Gill, Liver, Trunk kidney (X400). RBM: Rupture Basement Membrane; HP, HT: Hypertrophy, Hyperplasia; LF: Lamellar Fusion: H: Hepatocyte with ballooning degeneration; PD: Patchy degeneration; PN: Necrotic Pancreas; K: Kupffer cell.

\section{Gill}

The gill is the organ for respiration in fish. They are directly exposed to the external environment. So minute changes in the environment can directly affect the gills. The $\mathrm{H}$ and E stained gill sections of the control group showed normal histology. In group 1 (Fig. 2), the gills exposed to $\mathrm{NaAsO}_{2}$ showed hemorrhage, curling of secondary lamellae, desquamation, necrosis, and hyperplasia of epithelial cells. Group 2 (Fig. 3) the fish fed with $2.5 \mathrm{~g}$ of leaf extract $/ \mathrm{kg}$ of fish food showed normal primary lamellae, secondary lamellae, mucous cells, and epithelial cells. Group 3 (Fig. 4) fish exposed to $4.87 \mathrm{ppm}$ of $\mathrm{NaAsO}_{2}$ and fed with fish food mixed

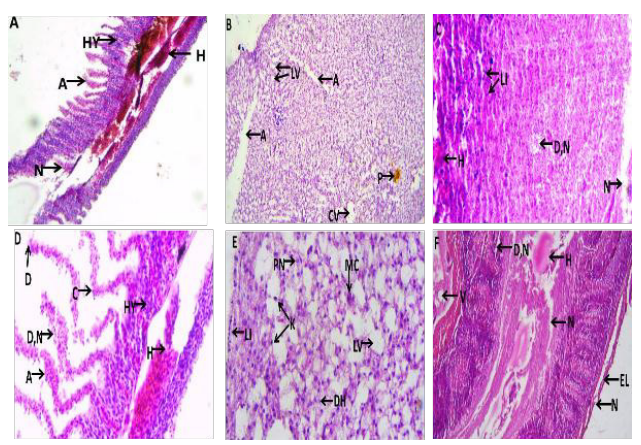

Fig. 2: Plate 2 Group 1: Treated with $4.87 \mathrm{ppm}$ of $\mathrm{NaAsO}_{2}$ and fed with normal fish food.

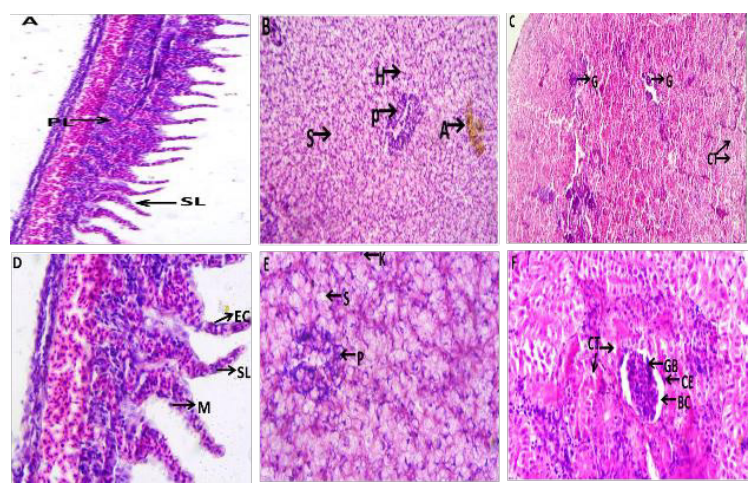

Fig. 3: Plate 3 Group 2: Fed with fish food mixed with $2.5 \mathrm{~g}$ of leaf extract $/ \mathrm{kg}$ of fish food. 
with $2.5 \mathrm{~g}$ of leaf extract showed tissue repairing activity such as decreased necrosis, hemorrhage, curling, and neoformed secondary lamellae. In group 4 (Fig. 5), the fishes were fed $5 \mathrm{~g}$ of leaf extract per kg of fish meal, which resulted in secondary lamellae curling and shortening, necrosis, hyperplasia, and hypertrophy of epithelial cells, deformed secondary lamellae, and bleeding. Ruptured basement membrane, hypertrophy, hyperplasia, lamellar fusion, and congestion were seen in group 5 (Fig. 6) treated with $\mathrm{NaAsO}_{2}$ and fed fish food with $5 \mathrm{~g}$ of leaf extract/kg of fish food.

\section{Liver}

The liver is the large vital organ in fish for detoxification, protein synthesis, and production of biochemicals necessary for digestion. Histological studies of the control fish liver fed with normal fish food showed normal pancreas, blood vessels, hepatocytes, sinusoids, and pigment. The $\mathrm{NaAsO}_{2}$ exposed group 1 (Fig. 2) showed fatty infiltration, apoptosis, pigment, central vein, pyknotic nuclei, mild congestion, an abundance of kupffer cell, leucocyte infiltration, and degenerated hepatocytes. Group 2 (Fig. 3) fish fed with fish food mixed with $2.5 \mathrm{~g}$ of leaf extract/kg of fish food showed normal hepatocyte, sinusoids, kupffer cells, pancreas, and pigment. Group 3 (Fig. 4) fish treated with 4.87 ppm of NaA$\mathrm{sO}_{2}$ and fed with fish food mixed with $2.5 \mathrm{~g}$ of leaf extract $/ \mathrm{kg}$ of fish food showed a reduction in fatty infiltration, vacuoles, and decreased necrosis. Group 4 (Fig. 5) fish fed with fish food mixed with $5 \mathrm{~g}$ of leaf extract showed mild necrosis, karyolysis, hepatocytes, sinusoids, apoptotic body, necrotic pancreas, and lipid vacuoles. Group 5 (Fig. 6) fish treated with $4.87 \mathrm{ppm}$ of $\mathrm{NaAsO}_{2}$ and fed with fish food mixed with $5 \mathrm{~g}$ of leaf extract showed hepatocytes with enlarged nuclei, necrotic bile duct and pancreas, pyknotic nuclei, patchy degeneration, and hepatic cells with ballooning degeneration.

\section{Kidney}

The kidney is responsible for excretion, removal of toxins and waste products from the body, and water balance maintenance. The control group (Fig. 1) fed with normal fish food showed normal glomerulus, bowman's space, collecting tubule, distal convoluted tubule, proximal convoluted tubule, and RBC. The $\mathrm{NaAsO}_{2}$ exposed group 1 (Fig. 1) fish's kidney showed epithelial lifting, necrosis, vacuole formation, degeneration and necrosis of cells, hemorrhage, and lymphocytic infiltration. In group 2 (Fig. 3), the fish fed with $2.5 \mathrm{~g}$ of leaf extract $/ \mathrm{kg}$ of fish food showed capsular endothelium, glomerular blood, bowman's capsule, and convoluted tubules. In group 3 (Fig. 4), fish treated with $\mathrm{NaAsO}_{2}$ and fed with fish food mixed with $2.5 \mathrm{~g}$ of leaf extract showed distinct glomerulus, bowman's space, and convoluted tubules. Group 4 (Fig. 5) fed with fish food mixed with $5 \mathrm{~g}$ of leaf extract showed karyolysis, karyorrhexis, necrosis, large cells with multi nuclei, mild glomerular congestion, hemorrhage, vacuole formation, and necrosis of renal vein. In group 5 (Fig. 6), the fish treated with $4.87 \mathrm{ppm}$ of $\mathrm{NaAsO}_{2}$ and fed with fish food mixed with $5 \mathrm{~g}$ of leaf extract showed tubular necrosis,

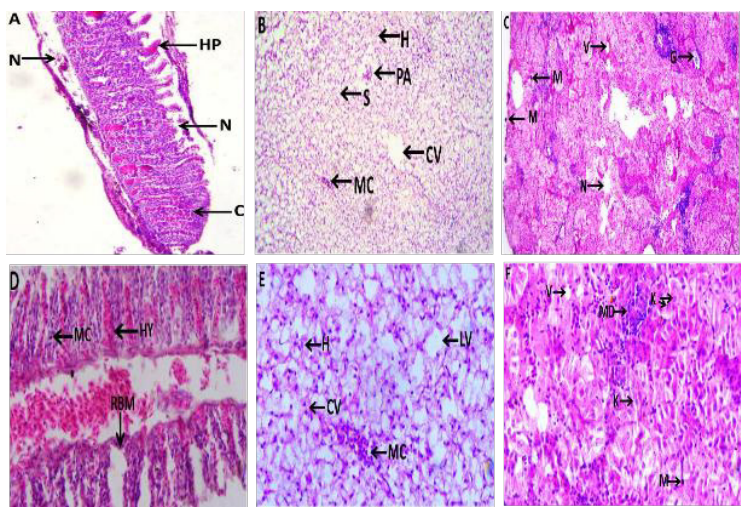

Fig 4: Plate 4 Group 3: Treated with $4.87 \mathrm{ppm}$ of $\mathrm{NaAsO} 2$ and fed with fish food mixed with $2.5 \mathrm{~g}$ of leaf extract $/ \mathrm{kg}$ of fish food.
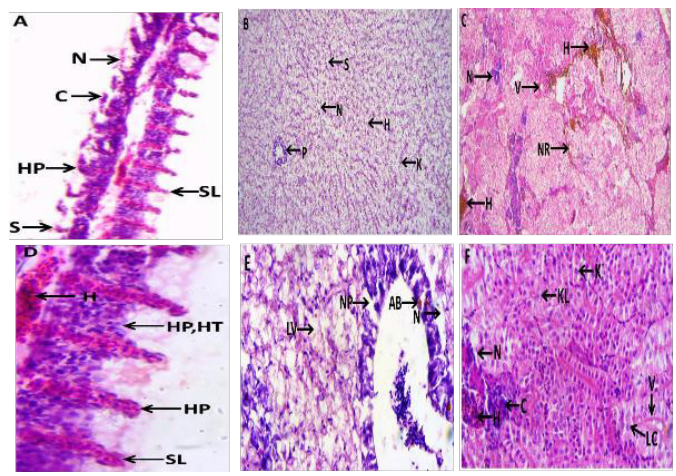

Fig 5: Plate 5 Group 4: Fed with fish food mixed with $5 \mathrm{~g}$ of leaf extract/ $\mathrm{kg}$ of fish food.
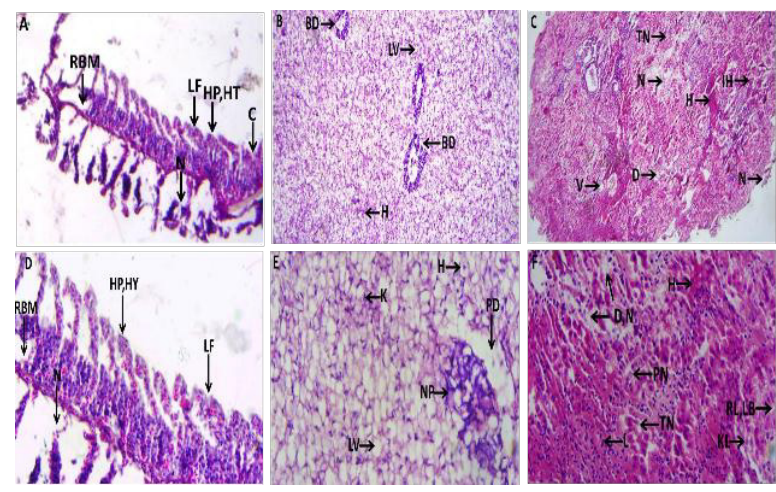

Fig 6: Plate 6 Group 5: Treated with $4.87 \mathrm{ppm}$ of $\mathrm{NaAsO} 2$ and fed with fish food mixed with $5 \mathrm{~g}$ of leaf extract $/ \mathrm{kg}$ of fish food. 
pyknotic nuclei, leucocytes, karyolysis, degeneration and necrosis, hemorrhage, intertubular hemorrhages, reduced lumen and loss of brush border in proximal convoluted tubules.

The control and various experimental groups are illustrated from plates 1 to 6 (Figs. 1 to 6). An increased level of damage is found in group 5 gill, liver, and kidney which is exposed to $\mathrm{NaAsO}_{2}$ and fed with fish food mixed with $5 \mathrm{~g}$ of G. pentaphylla leaf extract. This damage was higher when compared with fishes exposed to $\mathrm{NaAsO}_{2}$ and fed with normal fish food (group 1). Tissue repairing activity is evident in group 3 gill, liver, and kidney that are exposed to $\mathrm{NaAsO}_{2}$ and fed with fish food mixed with $2.5 \mathrm{~g}$ of leaf extract/ $\mathrm{kg}$ of fish food. $2.5 \mathrm{~g}$ of leaf extract with fish food has no effect on fish gill, liver, and kidney and it is shown in group 2. At the same time, $5 \mathrm{~g}$ of leaf extract fed with fish food caused damage to fish gill, liver, and kidney but the intensity of damage is lesser than $\mathrm{NaAsO}_{2}$ alone treated group.

\section{DISCUSSION}

The present study thus shows that $\mathrm{NaAsO}_{2}$ is very toxic to fish even at sub-lethal and short-term exposure. It can seriously affect fish health by causing harmful changes in the structure of the gill, liver, and kidney and $2.5 \mathrm{~g}$ of leaf extract of $G$. pentaphylla can repair the damaged gill, liver, and kidney tissues to a certain extend.

Arsenic is an influential environmental contaminant that has been reported as one of the most alarming chemicals released into the aquatic ecosystem as a result of the geogenic and anthropogenic processes (Gonzalez et al. 2006). Fishes are very sensitive to changes in their environment and seem to be specifically vulnerable to arsenic toxicity (Hamilton \& Buhl 1990), estimated LC50 values of arsenic in salmonids were found between 3 and $167 \mathrm{mg} . \mathrm{L}^{-1}$. The median lethal concentration $\left(96 \mathrm{~h} ; \mathrm{LC}_{50}\right)$ of arsenic $\left(\mathrm{NaAsO}_{2}\right)$ was calculated as $28.22 \mathrm{ppm}$ in a repeated semi-static test method by Ahmed et al. (2013). In the present investigation, the $96 \mathrm{~h}$ LC50 value of $\mathrm{NaAsO}_{2}$ in O. mossambicus was found to be $48.790 \mathrm{ppm}$. This difference in acute toxicity might be due to the difference in species, size of the fish, and environmental conditions.

The gills are important organs for respiration, osmoregulation, acid-base balance, and nitrogenous waste excretion (Heath 1987). After exposure to metals, an excessive amount of mucus was observed over the gills. Stress caused by variations in the environmental conditions induces the proliferation of mucus cells and increased mucous secretion (Fernandes et al. 2007). The histopathological changes in the gill such as edema, epithelial necrosis, the fusion of secondary lamellae, hemorrhage at filaments, hypertrophy of epithelial cells, and sloughing off of epithelial surface are the major effects reported in gills from the fish exposed to various types of pollutants (Mallatt 1985). Fishes exposed to nanometals, gills respond through the generation of edema with the lifting of gill lamellar epithelium by binding to Nap/ Kp-ATPase, which results in osmotic imbalance and inhibits the entry of toxins (Al-Bairuty et al. 2013, Pane et al. 2004, Fanta et al. 2003, Stagg \& Shuttleworth 1982). In the present study, the gill showed histological changes such as hemorrhage, curling of secondary lamellae, desquamation, necrosis, and hyperplasia of epithelial cells in O.mossambicus exposed to $\mathrm{NaAsO}_{2}$. These changes correlate with the above results.

The liver is the organ most associated with processes of detoxification and biotransformation, and due to its function, position, and blood supply, it is one of the organs most affected by contaminants in the water. The liver tissue of O.mossambicus showed focal lymphocytic and macrophage infiltration, congestion, vacuolization and shrinkage of hepatocytes, dilation of sinusoids, cloudy swelling, vacuolar degeneration, focal necrosis, and nuclear hypertrophy (Ahmed et al. 2013).

Vacuolation of hepatocytes has been shown as a common response to exposure of fish to a variety of different pollutants (Meyers \& Hendricks 1985). In the present study, after the exposure to $\mathrm{NaAsO}_{2}$, the liver showed fatty infiltration, apoptosis, pigment, central vein, pyknotic nuclei, mild congestion, an abundance of Kupffer cell, leucocyte infiltration, and degenerated hepatocytes. These changes were similar to the previous results.

Next, the kidney is one of the major organs that express toxic effects. The kidney of the fish receives the largest proportion of postbranchial blood, and therefore renal lesions might be expected to be good indicators of environmental pollution (Ortiz et al. 2003). The exposure of fish to toxic agents such as pesticides and heavy metals induces histological alterations in several components of the trunk kidney (Kendall 1975, Kirubagaran \& Joy 1988, Velmurugan et al. 2007). Similar to our observations, Gupta et al. (2016) displayed degeneration of renal tubules, a few necrotic cells in the hematopoietic tissue, and the presence of sinusoidal space in the $\mathrm{Cu}$ NPs treated $C$. carpio. They have also reported an increase in the space in between glomerulus and Bowman's capsule at higher dosage of NPs. In another study, alterations in Bowman's space, degeneration of renal tubule, vacuolation, and necrosis of hematopoietic tissue were reported by Kaya et al. (2016) in the kidney of O. niloticus after $\mathrm{ZnO}$ NPs exposure. In the present study epithelial lifting, necrosis, vacuole formation, degeneration and necrosis of cells, hemorrhage, and lymphocytic infiltration were observed in the trunk kidney tissues of fish exposed to 4.87 ppm of $\mathrm{NaAsO}_{2}$. The same changes were seen in the above results too. 
G.pentaphylla (Gin Berry) is a plant possessing various medicinal properties. It is believed to have wound-healing properties. A study of hepatoprotective activity of G. pentaphylla in Swiss albino mice against paracetamol-induced toxicity reported that there was a decrease in total protein after administration of ethanolic extracts of $G$. pentaphylla (Nayak et al. 2010). Another study revealed the effect of various fractions of $G$. pentaphylla (Retz.) DC leaves on the cell cycle and apoptosis of breast cancer cells viz. MCF-7 and MDA-MB-231 (Shoja et al. 2015). In the present study, fish gill, liver, and kidney exposed to $\mathrm{NaAsO}_{2}$ and fed with fish food treated with $2.5 \mathrm{~g}$ of leaf extract of $G$. pentaphylla have tissue repairing activity and $5 \mathrm{~g}$ of the same leaf extract have toxic effects on fish. From the above results, it is evident that $G$. pentaphylla leaf extract has tissue repairing activity against arsenic exposed toxicity.

The histological changes in the current study were observed in the gill, liver, and kidney of $O$. mossambicus. It was indicative that the fishes were responding differently to the different quantities of G. pentaphylla leaf extract. The pathological changes were induced in the gill, liver, and kidney, but the extent of damage varies depending upon the dose of G. pentaphylla. Overall, this information confirms that histopathological alterations can be repaired to a certain extend by an appropriate quantity of $G$. pentaphylla. The result of this study had proven that $2.5 \mathrm{~g}$ of leaf extract of G. pentaphylla alone caused no more damages in fish gill, liver, and kidney. But $5 \mathrm{~g}$ of the same leaf extract caused damage to tissues of all organs. When $2.5 \mathrm{~g}$ of leaf extract is fed with $4.87 \mathrm{ppm}$ of $\mathrm{NaAsO}_{2}$ exposed fish, it shows tissue repairing activity. $5 \mathrm{~g}$ of leaf extract to the same amount of $\mathrm{NaAsO}_{2}$ exposed fish caused severe damage than $\mathrm{NaAsO}_{2}$ alone exposed fish. Hence, it shows that 2.5 $\mathrm{g}$ of leaf extract is ideal for tissue repairing activity for $O$. mossambicus exposed to $\mathrm{NaAsO}_{2}$. An increased amount of this leaf extract alone can cause damage to tissues and if it is with $\mathrm{NaAsO}_{2}$ it can cause severe damages to the tissues. The results of the present study suggest that treatment with leaf extract of G.pentaphylla has tissue repairing activity in O.mossambicus gill, liver, and kidney at a dose of $2.5 \mathrm{~g}$ of leaf extract $/ \mathrm{kg}$ of fish food after exposed to $\mathrm{NaAsO}_{2}$. At the same time increase in the dose of this leaf extract to $5 \mathrm{~g}$, the $\mathrm{NaAsO}_{2}$ exposed O.mossambicus gill, liver and kidney had toxic effects and caused severe damages to the fish tissues. Hence it is evident that $2.5 \mathrm{~g}$ of leaf extract is ideal for tissue repairing in $O$. mossambicus after being exposed to $\mathrm{NaAsO}_{2}$.

\section{REFERENCES}

Ahmed, K., Habibullah, M., Elora, P., Mosammat, S.A. and Mohammad, S. K. 2013. Arsenic induced toxicity and histopathological changes in gill and liver tissue of freshwater fish, tilapia (Oreochromis mossambicus). Experim. Toxicol. Pathol., 65(6): 903-909.

Ahmed, K.K.M., Rana A.C. and Dixit V.K. 2005. Calotropis species (Ascelpediaceae): A comprehensive review. Pharmacogn. Mag., 16: 48-52.

Al-Bairuty, G.A., Shaw, B.J., Handy, R.D. and Henry, T.B. 2013. Histopathological effects of waterborne copper nanoparticles and copper sulfate on the organs of rainbow trout (Oncorhynchus mykiss). Aquat. Toxicol., 126: 104-115.

Argal, A. and Pathak, A.K. 2005. Antidiarrhoeal activity of Calotropis gigantea flowers. Indian J. Nat. Prod., 21: 42-44.

BibhaKumari, V., Amit, K.S., Jawaid, A.K., Ghosh, A., Hanping, W. and Gudrun, D. 2016. Toxicology of arsenic in fish and aquatic systems. Environ. Chem. Lett., 15: 43-64.

Chitme, H.R., Ghobadi, R., Chandra, M. and Kaushik, S. 2004. Studies on the anti-diarrhoeal activity of Calotropis gigantea $\mathrm{R}$. Br. in experimental animals. J. Pharm. Sci., 7: 70-75.

Cragg, G.M. and Newman, D.J. 2002. In: Iwu M.M. and Wootton, J.C. (Eds.) Drugs from Nature: Past Achievements, Future Prospects. Ethnomedicine and Drug Discovery. Elsevier Science, Amsterdam, pp. 23-37.

Domingo, J.L. 1995. Prevention by chelating agents of metal-induced developmental toxicity. Reprod. Toxicol., 9: 105-113.

Fanta, E., Rios, F.S., Romão, S., Vianna, A.C.C. and Freiberger S. 2003. Histopathology of the fish Corydoras paleatus contaminated with sublethal levels of organophosphorus in water and food. Ecotoxicol. Environ. Safety, 54: 119-130.

Fernandes, C.A., Fontaínhas-Fernandes, F. and Peixoto, M.A. 2007. .Bioaccumulation of heavy metals in Liza saliens from the EsmorizParamos coastal lagoon, Portugal. Ecotoxicol. Environ. Safety, 66(3): 426-431.

Finney, D.J. 1952. Statistical method in a biological assay. Statistical method in a biological assay. Charles Griffin and Co. Ltd, UK, pp. 236-252.

Gonzalez, H.O., Roling, J.A., Baldwin, W.S. and Bain, L.J. 2006. Physiological changes and differential gene expression in mummichogs (Fundulus heteroclitus) exposed to arsenic. Aquat. Toxicol., 77(1): 43-52.

Gupta, Y.R., Sellegounder, D., Kannan, M., Deepa, S., Senthilkumaran, B. and Basavaraju, Y. 2016. Effect of copper nanoparticles exposure in the physiology of the common carp (Cyprinus carpio): Biochemical, histological, and proteomic approaches. Aquacult. Fish., 1: 15-23.

Hamilton, S.J. and Buhl, K.J. 1990. Safety assessment of selected inorganic elements to fry Chinook salmon (Oncorhynchus tshawytscha). Ecotoxicol. Environ. Safety, 20(3): 307-324.

Heath, A.G. 1987. Water pollution and fish physiology. CRC Press, Boca Raton, Florida. 245

Kaya, H., Aydın, F., Gürkan, M., Yılmaz, S., Ates, M., Demir, V. and Arslan, Z. 2016. A comparative toxicity study between small and large size zinc oxide nanoparticles in tilapia (Oreochromis niloticus): Organ pathologies, osmoregulatory responses, and immunological parameters. Chemosphere, 144: 571-582.

Kendall, M.W. 1975. Acute effect of methyl mercury toxicity in channel catfish kidney. Bull. Environ. Contam. Toxicol., 13(5): 570-575.

Kirubagaran, R. and Joy, K.P. 1988. Toxic effects of three mercurial compounds on survival, and histology of the kidney of the catfish, Clarias batrachus. Ecotoxicol. Environ. Safety, 15: 172-279.

Klaassen, C.D. 1996. Heavy metals and heavy metal. The Pharmacol. Basis Therap., 9: 1592-1614.

Mallatt, J. 1985. Fish gill structural changes induced by toxicants and other irritants: A statistical review. Can. J. Fish. Aquat., 42: 630-648.

McIntyre, O. and Linton, T.K. 2011. Arsenic. Fish Physiol., 31: 297-349.

Meyers, T.R. and Hendricks, J.D. 1985. Histopathology. In: Rand, G.M. and Petrocelli, S.R. (eds), Fundamentals of aquatic toxicology, Hemisphere Publishing Corp, New York, pp. 283-331.

Mohammed, R., Rownak, J., Azad, A.K., Syeda, S., Mahbubur, R., Anita, R.C., Rahima, B., Zubaida, K., Mohammad, S.H., Afsana, K. and Emdadullah, M. 2010. A randomized survey of medicinal plants used 
by folk medicinal practitioners in six districts of Bangladesh to treat rheumatoid arthritis. Adv. Nat. Appl. Sci., 4: 124-127.

Nayak, S.S., Jain, R. and Sahoo, A.K. 2010. Hepatoprotective activity of Glycosmis pentaphylla against paracetamol-induced hepatotoxicity in Swiss albino mice. Pharm. Biol., 49(2): 111-117.

Ortiz, J.B., De Canales, M.L.G. and Sarasquete, C. 2003. Histopathological changes induced by lindane $(-\mathrm{HCH})$ in various organs of fishes. Sci. Mar., 67(1): 53-61.

Oudhia, M., Gungordu, A., Kucukbay, F.Z. and Guler, R.E. 2006. Monitoring the effects of water pollution on Cyprinus carpio in Karakaya dam Lake Turkey. Ecotoxicology, 15(2): 157-169.

Pane, E.F., Haque, A. and Wood, C.M. 2004. Mechanistic analysis of acute, $\mathrm{Ni}$-induced respiratory toxicity in the rainbow trout (Oncorhynchus mykiss): An exclusively branchial phenomenon. Aquat. Toxicol., 30: 11-24.
Ratnaike, R.N. 2003. Acute and chronic arsenic toxicity. Postgrad. Med. J., 79(933): 391-396.

Shoja, M.H., Neetinkumar, D.R., Pawan, G., Nayak, K.K., Srinivasan, R.C. and Mallikarjuna, R. 2015. Glycosmis pentaphylla (Retz.) DC arrests the cell cycle and induces apoptosis via caspase-3/7 activation in breast cancer cells. J. Ethnopharmacol., 168: 50-60.

Sivarajan, V.V. and Balachandran, I. 1994. Ayurvedic Drugs and Their Plant Sources. Oxford and IBH Publishing, London, UK, pp. 527-544.

Stagg, R.M. and Shuttleworth, T.J. 1982. The effects of copper on ionic regulation by the gills of the seawater-adapted flounder (Platichthys flesus L.). J. Comp. Physiol., 149: 83-90.

Velmurugan, B., Selvanayagam, M., Cengiz, E.I. and Unlu, E. 2007. The effects of fenvalerate on different tissues of freshwater fish, Cirrhinus mrigala. J. Environ. Sci. Health B, 42(2): 157-163. 